\title{
Pneumonia in Children
}

\author{
Irena Wojsyk-Banaszak and Anna Bręborowicz
}

Additional information is available at the end of the chapter

http://dx.doi.org/10.5772/54052

\section{Introduction}

Pneumonia causes substantial morbidity in children worldwide and is a leading cause of death in children in the developing world. The incidence of pneumonia is the highest in children under 5 years of age and in recent years the incidence of complicated and severe pneumonia seems to be increasing.

Etiological factors vary with age, source of infection (community vs. hospital acquired pneumonia) and underlying host defects (e.g immunodeficiency). Viruses are the most common etiological factors in preschool children, although in many cases more than one causative agents can be identified. There are several emerging pathogens in community acquired pneumonia in children: virulent strains of Streptococcus pneumoniae that are not present in currently available vaccines, Panton-Velentine leucocidin producing Staphylococcus aureus, human Bocaviruses and metapneumoviruses being the most important.

Diagnosis in most of milder cases of community acquired pneumonia is based on clinical judgement alone, since laboratory tests and radiologic examination do not provide clues concerning etiology. Children with severe pneumonia, hospital acquired pneumonia and immunocompromised children require invasive diagnostic approach.

Treatment of mild and moderate cases consists in supportive care and antibiotic treatment. First-line recommended therapy in previously healthy children regardless of age is amoxicillin, as it provides sufficient coverage against the most common invasive bacterial pathogen, namely Streptococcus pneumoniae. For hospital acquired pneumonia initial empiric treatment should be based on local antimicrobial susceptibility patterns, and modified adequately as soon as the results of microbiological tests are available.

Despite the fact, that if properly diagnosed and treated pneumonia resolves with no residual changes, in some cases due to pathogen virulence and/or host susceptibility its course might 
be complicated with pleural effusion and empyema, pneumoatocele, lung abscess or necrotizing pneumonia. A recognized complication of severe pneumonia is hyponatremia and SIADH (Syndrome of Inappropriate Antidiuretic Hormone Secretion).

Burden of pneumonia can be diminished using preventive measures ranging from the simplest infection control methods like hand washing, limiting exposure to infectious cases, limiting exposure to tobacco smoke, vaccinations to passive immunization in selected cases.

\section{Definition}

Pneumonia is defined as an inflammation of lung tissue due to an infectious agent. Commonly used clinical World Health Organization operational definition is based solely on clinical symptoms (cough or difficulties in breathing and tachypnoea) [1]. In the developing world the term Lower Respiratory Tract Infection (LRTI) is widely used instead of pneumonia, because of poor access to x-ray and difficulties in radiological confirmation of diagnosis.

Depending on the place of acquisition pneumonia can be divided into:

a. Community Acqiured Pneumonia (CAP)

b. Hospital Acquired Pneumonia (HAP).

Recently a third type - Health Care Associated Pneumonia (HCAP) has been distinguished in adult patients.

The significance of this classification is based on its clinical utility since in most cases pathogens responsible for $\mathrm{CAP}$ and $\mathrm{HAP}$ are different, warranting varying approach and empiric treatment.

\section{Community acquired pneumonia}

CAP can be defined as pneumonia in previously healthy children caused by an infectious agent contracted outside the hospital. The common clinical practice is to confirm the diagnosis by radiological findings of consolidations.

\section{Epidemiology}

Globally the incidence of pneumonia in children $<5$ years in developing countries is 0.28 episodes per child - year (150 mln/year), compared to 0.05 episodes per child - year in developed countries [2]. Pneumonia is responsible for $18 \%$ of death ( $2 \mathrm{mln} / \mathrm{year}$ ) in young children worldwide, mostly occurring in impoverished countries with limited access to healthcare system. In more affluent societies pneumonia is rarely fatal, it leads however to 
substantial morbidity. Incidence of radiologically confirmed pneumonia in previously healthy children in Europe is 144-147/100,000 children/year and decreases with age, being the highest in children $<5$ years (328-338/100,000/year and 421/100,000/year in those aged 0-2 years) [3,4]. The rates of hospitalization due to pneumonia in this age group were $122 / 100,00 /$ year in children $\leq 16$ and 287/100,000/year in those $\leq 5$ [4]. British studies show the rate of CAP presenting to General Practitioners in children $<5$ to be 191/100, 000 person years [5], probably due to the fact that more severely sick children would present directly to the hospital. In a German study incidence of hospitalized pneumonia was 300/100,000/year in children 0-16 and 658/100,000/year in those aged 0-5. In 23\% of those cases underlying conditions were present, and it is possible that many children with bronchiolitis were classified as having pneumonia [6].

Since introduction of conjugate pneumococcal vaccine (PCV7) to national immunization programs in the USA and Europe the incidence of pneumococcal pneumonia has decreased (by $65 \%$ in the USA) and rates of CAP hospitalizations have decreased for children $<1$ but seem to be increasing for children $>5$ [7-9]. At the same time the incidence of severe pneumonia requiring hospital management as well as complicated pneumonia seems to be increasing. Between 1997 and 2006, the rate of local complications of CAP increased by $77.8 \%$ (5.4 and 9.6 cases per 100000 population, respectively). Empyema accounted for $>97 \%$ of all local complications $[8,9]$.

\section{Etiology}

Organisms causing pneumonia are varied and include bacteria, viruses, fungi and protozoans. Most cases of pneumonia are preceded by acute viral bronchitis. Viruses facilitate infections with pathogenic microorganisms colonizing nasopharynx. These pathogens include Streptococcus pneumoniae, Haemophilus influenzae and Moraxella catarrhalis. Previous colonisation with Streptococcus mitis and anaerobic cocci Peptostreptococcus anaerobius may have protective effect against pathogenic strains.

Etiological factor of pneumonia can be identified in no more than $65-86 \%$ patients combining multiple diagnostic tools including culture, serology and PCR [7,11]. In everyday clinical practice these methods are rarely used and treatment remains empiric based on national and international guidelines.

Viruses are responsible for $30-67 \%$ cases of CAP, and are the most common in children $<2$. The most frequently identified are respiratory syncytial virus (RSV) isolated in $13-29 \%$ and rhinovirus (3-45\%) either in combination with bacteria or alone. Other viruses responsible for pneumonia comprise adenovirus (1-13\%), influenza (4-22\%) and parainfluenza virus (3-10\%), rhinovirus (3-45\%), human metapneumovirus (5-12\%), human bocaviruses (5-15\%). The less common are enterovirus, varicella-, herpes- and cytomegalovirus [7,11-13]. In older children bacterial infections are more frequent: Streptococcus pneumoniae being the leader (30-44\% of CAP) followed by Mycoplasma pneumoniae (22-36\%) and Chlamydophila pneumoniae $(5-27 \%)[7,11,13-16]$. Streptococcus pneumoniae remains the leading cause of severe pneumo- 
nia requiring hospitalization even in countries with reduced rates of invasive pneumococcal disease [17]. Since introduction of PCV7 the most common pneumococcal isolates are 1 (predominantly responsible for empyema), 19A, 3, 6A and 7F (all included in 13-valent vaccine) [18]. Contrary to previous reports Mycoplasma pneumoniae seems to be equally frequent in school and preschool children [11,13]. Less common bacterial causes of CAP in children include Haemophilus influenzae type B (5-9\%), Staphylococcus aureus, Moraxella catarrhalis (1.5-4\%), Bordatella pertussis, Streptococcus pyogenes (1-7\%), Chlamydia trachomatis and a new pathogen identified in the 1990ies - Simkania negevensis $[7,12]$. Unlike in adults Legionella pneumophila is a rare cause of CAP in children [19].

In malaria-endemic regions of tropical Africa a challenging etiological factor of pneumonia is multidrug-resistant non typhoidal Salmonella, and in regions where tuberculosis is endemic it is increasingly being recognized as a cause of acute pneumonia [20].

$8-40 \%$ of cases represent a mixed viral - bacterial or bacterial - bacterial infection $[3,4,7,12,16,19]$. Primary viral infection predisposes to bacterial pneumonia: influenza epidemics in developed countries coincide with epidemics of Streptococcus pneumoniae and Staphylococcus aureus pneumonias and measles or RSV infections contribute to increased pneumonia mortality in developing countries [2].

\section{Risk factors for cap}

There are several known risk factors for CAP to consider in addition to immunization status, epidemiological data and exposure to other children, especially preschoolers. Underlying comorbidities like diabetes mellitus, asplenia or splenic dysfunction, chronic cardiac disease, nephrotic syndrome, severe liver disease are risk factors for invasive pneumococcal disease including pneumonia. Other risk factors for CAP include: asthma, history of wheezing episodes, otitis media treated by tympanocentesis in the first 2 years of life (risk factor for children $<5$ ), tobacco smoke exposure, malnutrition, immunological deficits (primary or secondary), mucocilliary dysfunction (cystic fibrosis, cilliary dyskinesia), congenital malformation of airways, impaired swallowing, microaspiration, gastroesophageal reflux, neuromuscular disorders, treatment with gastric acid inhibitors (risk factor in adults, in children its role was confirmed in one study). Environmental factors like indoor air pollution caused by cooking and heating with biomass fuels (like wood or dung), living in crowded conditions and parental smoking also increase a child's susceptibility to pneumonia [1,7]. Tobacco smoke exposure has been found to increase risk of hospitalization for pneumonia in children $<5$ [21]. Conditions predisposing to severe pneumonia include age $<5$ and prematurity (24-28 GA) [11]. Viral infections, especially influenza and prior antibiotic exposure additionally predispose to pneumococcal and staphylococcal pneumonia. Antibiotics alter bacterial microflora in the airways destroying commensal bacteria like alfa-hemolytic Streptococci while viruses release neuraminidase and other enzymes promoting adherence and expression of pneumococcal receptors on host cells like platelet activating factor receptor or CD14 [17,22]. 


\section{Clinical manifestations}

Typical clinical symptoms of pneumonia consist of:

- cough $(30 \%$ of children presenting to outpatient clinic with cough, after excluding those with wheeze, have radiographic signs of pneumonia, and cough was reported in $76 \%$ of children with CAP) $[13,23]$. It should be noted that sputum production in preschool children is rare, because they tend to swallow it.

- fever (present in 88-96\% of children with radiologically confirmed pneumonia) [13]

- toxic appearance

- signs of respiratory distress: tachypnoe (table 1), history of breathlessness or difficulty in breathing - chest retractions, nasal flaring, grunting, use of accessory muscles of respiration. Tachypnoe is a very sensitive marker of pneumonia. $50-80 \%$ of children with WHO defined tachypnoe had radiological signs of pneumonia, and the absence of tachypnoe is the best single finding for ruling out the disease $[13,23]$. In children $<5$ tachypnoe had sensitivity of $74 \%$ and specificity of $67 \%$ for radiologically confirmed pneumonia, but its clinical value was lower in the first 3 days of illness. In infants $<12$ months respiratory rate of 70 breaths/min had a sensitivity of $63 \%$ and specificity of $89 \%$ for hypoxemia [7].

\begin{tabular}{cc}
\hline Age & Respiratory rate/minute \\
\hline $0-2$ months & $" />60$ \\
\hline $2-12$ months & $" />50$ \\
\hline $1-4$ years & $" />40$ \\
\hline$\geq 5$ years & $" />30$ \\
\hline
\end{tabular}

Table 1. Tachypnoe defined according to WHO criteria [1]

- chest pain,

- abdominal pain (referred pain from the diaphragmatic pleura might be the first sign of pneumonia in little children) and/or vomiting

- headache

Based on clinical symptoms pneumonia can be divided into severe pneumonia that warrants hospitalization and mild, moderate or non-severe. Signs of severe pneumonia differ with age and according to BTS comprise of: temperature $38,5{ }^{\circ} \mathrm{C}$, respiratory rate $>70$ breaths/ minute in infants and $>50$ breaths/minute in older children, moderate to severe recessions in infants and severe difficulty in breathing in older children, nasal flaring, cyanosis, intermittent apnoea, grunting, not feeding in infants and signs of dehydration in older children, tachycardia, capillary refill time $\geq 2 \mathrm{~s}$ [7]. Agitation may be the sign of hypoxemia. Table 2 presents a simplified approach recommended by WHO to be implemented in developing world to help field healthcare workers assess the need for hospital referral. 
Physical examination:

- crackles (present in 33-90\% of children with pneumonia), diminished breath sounds over affected site, bronchial breath sounds specific for lobar consolidation, absent breath sounds and dullness to percussion suggestive of effusion. A pleural rub may be heard if pneumonia is accompanied by pleuritis. Crackles and bronchial breath sounds have sensitivity of $75 \%$ and specificity of $57 \%$ in pneumonia diagnosis [7].

- presence of wheeze, especially in the absence of fever, makes the diagnosis of typical bacterial pneumonia unlikely [24]. It is however a common sign in viral and Mycoplasma pneumonia (up to $30 \%$ ) infection [7].

- combining several clinical symptoms into diagnostic algorithm improves sensitivity and specificity of diagnosis. WHO criteria for defining pneumonia (cough or difficulties in breathing and tachypnoea) investigated in a Brasilian study of 390 children have sensitivity of $94 \%$ for children $<2$, and $62 \%$ for children $\geq 2$ and specificities of $20 \%$ and $16 \%$ respectively. Adding fever improved specificity to $44 \%$ and 50\% [25]. In an Australian study of febrile children $<5$ presenting to tertiary emergency department, clinical indicators of pneumonia confirmed radiologically and microbiologically comprised an unwell appearance, fever $\geq 390 \mathrm{C}$, breathing difficulties, chronic disease, prolonged capillary refill time, tachypnoe, crackles on auscultation and lack of antipneumococcal vaccination [26].

It is important to note that no clinical or radiological sign either alone or in combination, is sensitive and specific enough to differentiate between viral, atypical or typical bacterial etiology of pneumonia.

\begin{tabular}{cc}
\hline Pneumonia/non severe pneumonia & $\begin{array}{c}\text { Cough } \\
\text { Problems with breathing } \\
\text { Tachypnoe * }\end{array}$ \\
\hline Severe pneumonia & No signs of severe pneumonia present \\
\hline Very severe pneumonia & $\begin{array}{c}\text { Signs of pneumonia } \& \geq 1 \\
\text { - lower chest wall indrawing }\end{array}$ \\
& - nasal flaming \\
& - expiratory grunting \\
\hline *ook table 1 & - no signs of very severe pneumonia \\
\hline
\end{tabular}

Table 2. Severity of pneumonia - WHO classification $[2,27]$ 


\section{Additional tests}

1. Pulsoximetry should be performed in all children with pneumonia since its results facilitate assessment of severity and therefore the need for hospital referral. Pulsoximetry should be definitely performed in all children admitted to hospital [7].

2. Laboratory studies

3. Determination of etiology - microbiological investigations

Determining the specific pathogen in children with CAP is difficult. Little children do not expectorate sputum, nasopharyngeal swabs are not reliable since bacteria present in the upper airways are not necessarily the same as those causing pneumonia. Invasive diagnostic tools, though efficacious are hardly acceptable in otherwise healthy children most of whom improve with empiric treatment. British Thoracic Society (BTS) standards, Pediatric Infectious Diseases Society guidelines as well as American Academy of Pediatrics Policy statements do not recommend microbiological investigation of the child with pneumonia treated as an outpatient. For patients admitted to the hospital, especially those admitted to ICU and those with complications of CAP, microbiological diagnosis should be attempted.

- blood cultures are positive in $<10 \%$ of patients with pneumonia and $<2 \%$ of patients treated in the outpatient setting. They should nevertheless be performed since if positive, they provide information on CAP etiology and antibiotic resistance $[7,19]$. In children with complicated pneumonia prevalence of bacteremia vary from $7.8 \%$ to $26.5 \%$ in pneumonia with parapneumonic effusion [19].

- nasopharyngeal aspirates or nasal lavage samples may be helpful in identifying respiratory viruses including respiratory syncytial virus, parainfluenza virus, influenza virus and adenovirus by immunofluorescence method. The results of these tests are particularly useful for cohorting infected children during outbreaks and for epidemic purposes [7].

- sputum is difficult to obtain in small children. A reliable sputum sample, as opposed to saliva, contains $<10$ epithelial cells per low-powered field [35]. Sputum induced by inhalation with $5 \%$ hypertonic saline has much higher bacterial yield and seems to be a valuable tool in microbiological diagnosis in children with CAP [36].

- children who require mechanical ventilation should have tracheal aspirates taken for Gram stain and culture at the time of endotracheal tube placement [19].

- aspirated pleural fluid should be sent for microscopy, culture and antigen detection. Cultures are positive in $9 \%-18 \%$ of cases (sensitivity $23 \%$, specificity $100 \%$ ) [7, 37]. Pneumococcal antigen detection in pleural fluid has sensitivity of $90 \%$ and specificity of $95 \%$ [38]. Pleural fluid should be checked for Mycobacteria.

- pneumococcal antigens detection in urine is not specific, as it is often positive in young children with nasopharyngeal colonization

- Serological testing: fourfold rise in antibody titers in complement fixation test is a golden diagnostics standard, unfortunately not useful for treatment guidance. In many laborato- 
ries enzyme linked immunosorbent assays (ELISA) has replaced complement fixation tests as less time consuming. Positive anti Mycoplasma IgM antibody titer 9-11 days from the onset of illness is also suggestive of recent infection. Cross reactions with adenovirus and Legionella pneumophila have been described [23]. Cold agglutinins measurement value is limited - in school children the positive predictive value for Mycoplasma of a rapid cold agglutinin test was 70\% [7]. In Chlamydophila pneumoniae infection IgM rise is observed after 3 weeks and IgG rise after 6-8 weeks.

- Legionella pneumophila urinary antigen detection remains golden standard for the diagnosis of legionellosis. The test remains positive for weeks after acute infection. Urinary antigen is positive only in case of infection with serogroup 1 . Antigens are excreted in urine at the beginning of the second week of illness. Quick diagnostic tests are commercially available with sensitivity of $80 \%$ and specificity of $99-100 \%$. Infection with serogroup 1 can be excluded when the results of 3 consecutive urine samples are negative.

- real time Reverse Transcriptase Polymerase Chain Reaction (RT-PCR) can be used for investigating the etiology of pneumonia. The advantage of this method is the availability of results on the same day. It does not however provide information on bacterial sensitivity nor is readily available outside research settings. Pneumolysin based PCR has been increasingly used to detect Streptococcus pneumoniae in blood and pleural fluid with sensitivity of $100 \%$ and specificity of $95 \%$ [7]. Measuring bacterial load with RT-PCR may help predict the outcome of CAP as adult patients with bacterial load $>1000$ copies/mL were at higher risk for sepsis, respiratory insufficiency and death [39].

\section{Chest radiography}

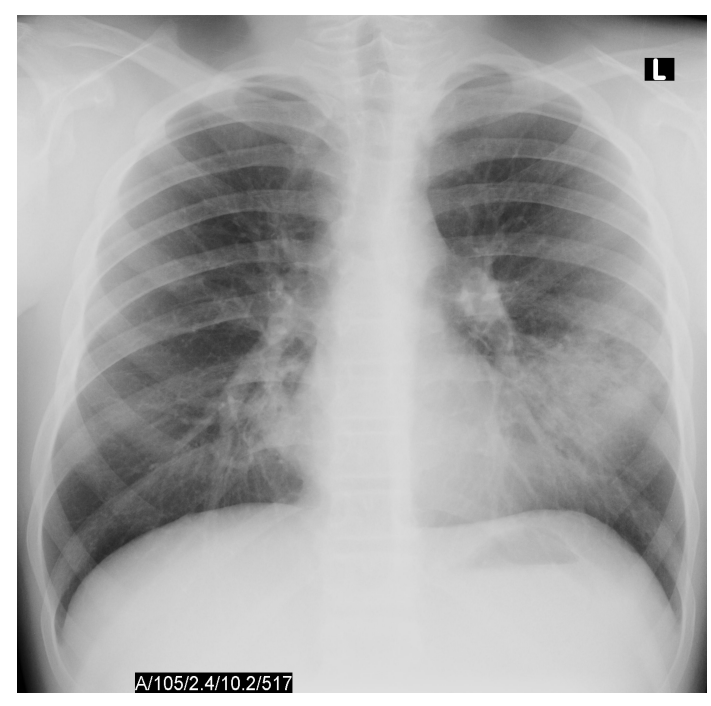

Figure 1. Alveolar consolidations in the left lower lobe and in the right lower lobe. Mycoplasma pneumoniae pneumonia 


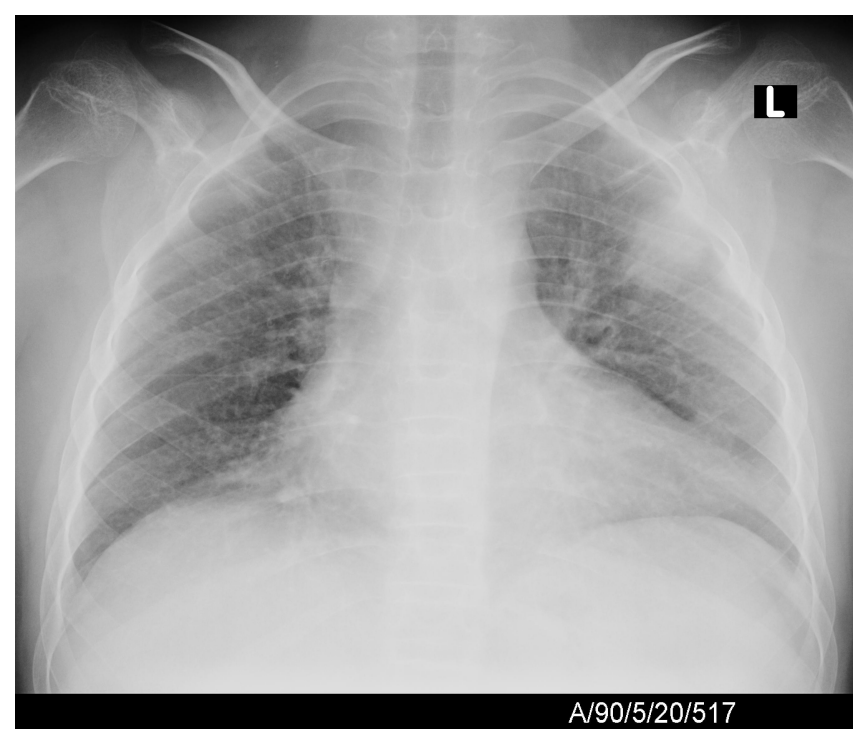

Figure 2. Round focus of consolidation in the left upper lobe. Pneumonia.

\section{Management}

Most children with CAP can be safely managed on outpatient basis. Indications for hospital referral comprise:

- clinical signs of severe pneumonia (listed above),

- signs of sepsis or septic shock

- young age $-<6$ months of life

- hypoxemia - oxygen saturation $<92 \%$ (according to BTS) or $<90 \%$ (according to AAP and PIDS), $\mathrm{PaO}_{2}<60 \mathrm{mmHg}$ and $\mathrm{PaCO}_{2}>50 \mathrm{mmHg}$, central cyanosis

- underlying conditions eg. congenital heart defect, cystic fibrosis, bronchopulmonary dysplasia, immune deficiencies

- diffuse radiological changes: multilobar pneumonia, pleural effusion

- outpatient treatment failure

- CAP caused by pathogen with increased virulence eg. MRSA(PIDS)

- parents' inability to manage the illness at home 
Children who are not improving despite treatment and present with impeding respiratory failure or shock should be admitted to Intensive Care Unit. Criteria for ICU admission comprise:

- need for invasive mechanical ventilation or non-invasive positive pressure ventilation,

- fluid refractory shock

- hypoxemia requiring $\mathrm{FiO}_{2}$ greater than inspired concentration or flow feasible in general care area; pulsoximetry measurements $\leq 92 \%$ with inspired oxygen of $\geq 0.5$ (according to BTS) or $\geq 0.6$ (according to PIDS)

- altered mental status due to hypercarbia, hypoxemia or as a result of pneumonia

- recurrent apnea, grunting or slow irregular breathing

- rising respiratory rate and heart rate with clinical evidence of severe respiratory distress and exhaustion with or without hypercarbia [7,19]

\section{General management}

All children treated for pneumonia should be reassessed in 48 hours if there is no clinical improvement or deterioration and persistence of fever. It is important that parents of children treated at home have clear written instructions on fever management, preventing dehydration, recognizing signs of deterioration as well as further access to healthcare professionals [7].

Hospitalized hypoxemic children should be given oxygen to maintain oxygen saturation > $92 \%$. Dehydrated children should be provided adequate amount of oral fluids and if unable to drink should receive intravenous fluids. Their electrolytes and creatinine serum levels should be measured on daily basis. Up to date there have been no studies proving beneficial effects of chest physiotherapy in children with pneumonia and therefore chest physiotherapy should not be performed.

A child should improve as evaluated by clinical symptoms and laboratory inflammatory markers in 48-72 hours after initiation of adequate treatment. Failure to improve warrants further investigation for possible complications, resistant microorganisms or alternative diagnosis.

\section{Antibiotic treatment}

There is no consensus between experts whether all children with CAP should receive antibiotics. According to BTS guidelines issued in 2011 all children diagnosed with pneumonia should be treated with antibiotics. This is in contrast to previous guidelines stating that if viral etiology is suspected antibiotics might be withheld provided that the child is reas- 
sessed in 24-48 hours. The reason for this change, despite the obvious concerns of increasing antibiotic resistance among bacteria as well as possible adverse reactions in children unnecessarily treated with antibiotics, is the fact that based on clinical, laboratory and radiological markers, either alone or in combination, a reliable distinction between viral and bacterial infection is impossible. Children $<2$ especially with a history of conjugate pneumococcal vaccination and with mild symptoms of lower respiratory tract infection are unlikely to have pneumonia. In these children antibiotics might be withheld provided reassessment of the child is made if the symptoms persist or deterioration occurs [7]. PIDS guidelines, on the contrary, state that preschool children with $\mathrm{CAP}$ do not routinely require antibiotic therapy since pneumonia in this age group is predominantly of viral origin [19].

Antibiotic of choice for CAP treated in community is amoxicillin $90 \mathrm{mg} / \mathrm{kg} /$ day applied in two doses for 5-10 days. Results from two randomized trials on short course (3 days) oral antibiotics performed on infants in developing countries are difficult to interpret since many of these children had bronchiolitis with wheeze or upper respiratory tract infection and did not need antibiotics at all $[43,44]$. Amoxicillin is effective against the majority pathogens responsible for CAP in children. It is well tolerated and affordable. Alternatives are co-amoxiclav, cefaclor and macrolides. For Streptococcus pneumoniae resistant to penicillin with MICs up to $4.0 \mu \mathrm{g} / \mathrm{mL}$ preferred treatment consists in ceftriaxone, and for MICs $>4.0 \mu \mathrm{g} / \mathrm{mL}$ in vancomycin, linezolid or clindamycin though resistance to clindamycin seems to be increasing amounting to $15-40 \%$ in certain geographic regions [19]. It should be noted that interpretation of in vitro susceptibility tests to penicillin depends on the route of administration. Intravenously administered penicillin can achieve tissue concentrations effective against organisms with minimal inhibitory concentration (MICs) $\leq 2.0 \mu \mathrm{g} / \mathrm{mL}$, possibly effective for strains with MICS of $4 \mu \mathrm{g} / \mathrm{mL}$ and not likely to be effective for strains with MICS $\geq 8 \mu \mathrm{g} / \mathrm{mL}$. For orally administered penicillin corresponding values are $<0.06 \mu \mathrm{g} / \mathrm{mL}, 0.12-1.0 \mu \mathrm{g} / \mathrm{mL}$, and $\geq 2.0 \mu \mathrm{g} / \mathrm{mL}$ for resistant strains [19]. Clinical laboratory standards vary depending on the region. Those given above, were issued jointly by Infectious Diseases Society of America (IDSA) and American Thoracic Society (ATS). BTS recommends cut off values for intravenously administered penicillin of $<0.1 \mathrm{mg} / \mathrm{L} ; 0.1-1.0 \mathrm{mg} / \mathrm{L}$ and $>1.0-4.0 \mathrm{mg} / \mathrm{L}$ and European Respiratory Society (ERS) recommends MIC breakpoints $<0.5 \mathrm{mg} / \mathrm{L} ; 0.5-2.0 \mathrm{mg} / \mathrm{L}$ and $>2.0 \mathrm{mg} / \mathrm{L}$ respectively $[17,19]$. PIDS recommends levofloxacin for children from 6 months of age as preferred choice for oral therapy [19]. Macrolide antibiotics may be added if Mycoplasma pneumoniae or Chlamydophila pneumonia are suspected when the child is not improving after 24 - 48 hours or in very severe cases. They are not recommended as first choice antibiotics because up to $40 \%$ of currently isolated in USA strains of S. pneumoniae are resistant to macrolides [19].

As is the case with indications for antibiotics in CAP there is no consensus as to how they should be administered. According to BTS guidelines if the child is feeding well and not vomiting, antibiotics should be given orally. Children with moderate pneumonia admitted because of respiratory distress can be treated with oral antibiotics and discharged when fever and respiratory distress subside $[7,45]$. Intravenous route of antibiotic administration is 
reserved for children with severe, complicated pneumonia or sepsis for whom intravenous amoxicillin, co-amoxiclav, cefuroxime, cefotaxime or ceftriaxone are recommended. According to PIDS guidelines however all children treated in hospital should receive antibiotics intravenously to provide reliable blood and tissue concentrations [19]. In hospitalized children suspected of $S$. aureus infection vancomycin or clindamycin should be added to beta-lactam therapy. For children with penicillin allergy recommended drugs are cephalosporins and in case of type-I allergic reactions macrolides, vancomycin or clindamycin are suggested. In children who do not tolerate vancomycin or clindamycin, linezolid may be administered [19]. Antibiotic should be changed according to results of culture and sensitivity if these tests are positive. As soon as the child's condition improves, a switch to oral antibiotics should be considered [7].

\section{Complications}

\subsection{Empyema and parapneumonic effusion}

Parapneumonic effusion is defined as pleural fluid collection in association with underlying pneumonia and empyema is defined as the accumulation of purulent fluid in the pleural cavity [46]. Incidence of parapneumonic effusion is increasing (by $70-100 \%$ between 1990s and the beginning of the present century), affecting $0.6 \%$ of all children with CAP, $2-10 \%$ of pneumonia hospitalizations and $1 / 3$ of pneumococcal pneumonia hospitalizations [47-50]. Predominant etiological factors are S. pneumonia (serotype 1,3,14,19A) responsible for $10-66 \%$ of empyema cases, S. aureus including MRSA (4-30\%) and S. pyogenes. The less common include Haemophilus influenzae, Mycobacterium spp, Pseudomonas aeruginosa, anaerobes, Mycoplasma pneumonia and fungi [28,46,47,51,52]. Fluid collection is usually unilateral. Empyema classically exhibits three stages:

- Exudative - pleural space contains free flowing fluid with a low white cell count, so called parapneumonic effusion that results from increased vascular permeability and migration of neutrophils, lymphocytes and eosinophils in the course of inflammatory process.

- Fibrinopurulent occurs 5-10 days from the onset of the disease and consists in the deposition of fibrin in the pleural space that leads to septation and formation of loculations. The number of white cells increases (empyema) in response to bacterial invasion across the damaged epithelium and if left untreated it progresses into

- Organizing - includes infiltration of fibroblasts and evolution of thick elastic membrane in the pleural cavity (the "peel"). These membranes may impair lung function and prevent lung re-expansion. Empyema at this stage may heal spontaneously or a chronic empyema may develop [46].

Some authors distinguish "pleuritis sicca stage" that precedes exudative stage, not necessarily leading to it [53]. 
Empyema should be suspected in every child with pneumonia with a history of prolonged fever, tachypnoe, pain on abdominal palpation, pleuritic chest pain, splinting of the affected side and persistence of high serum C-reactive protein levels [50]. On physical examination asymmetry of breath sounds, unilateral decreased chest wall expansion, dullness to percussion might be appreciated [27]. In some children with pneumonia empyema may develop during intravenous antibiotic treatment [50]. One of the identified risk factors for bacterial empyema is precedent varicella [49].

Chest radiographs show homogenous opacity over the entire lung (large effusion) (Figure 3). In smaller effusions an ascending rim of fluid along the lateral chest wall (meniscus sign) occurs. Costophrenical angle obliteration is the first sign of pleural effusion. Based on radiograph it is not possible to distinguish effusion from empyema [47]. A method of choice for radiologic evaluation of patients with parapneumonic effusion and empyema is ultrasonography. It helps estimate the amount of fluid, its echogenicity, detects loculations and fibrin strands and is used to guide invasive procedures [28]. Chest CT should not be routinely performed, it may be useful however for diagnosis of underlying pathology eg. tumor in the mediastinum or lung abscess [46,53].

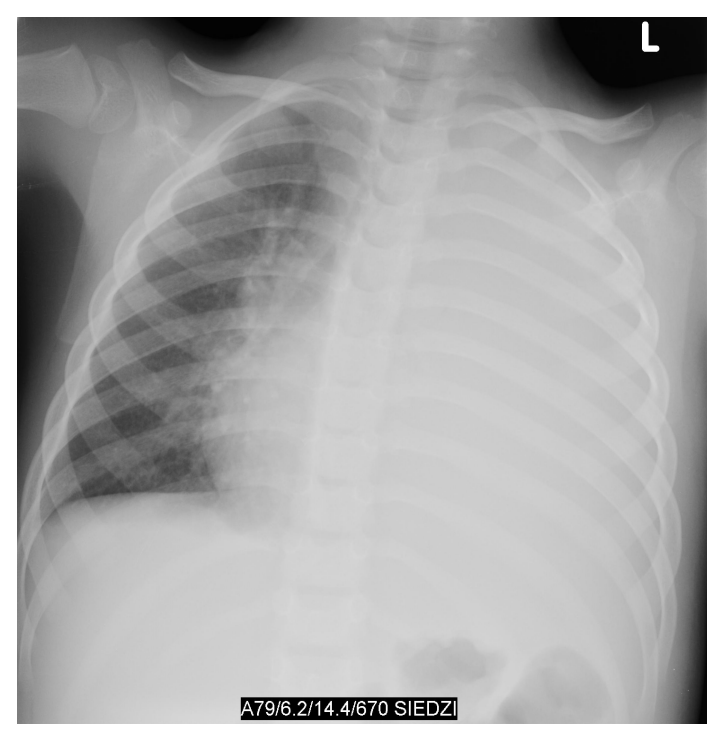

Figure 3. Opacification of left hemithorax with mediastinal shift to the opposite side. Alveolar consolidations in the central field of the right lobe. Lobar pneumonia with pleural effusion caused by Streptococcus pneumoniae 


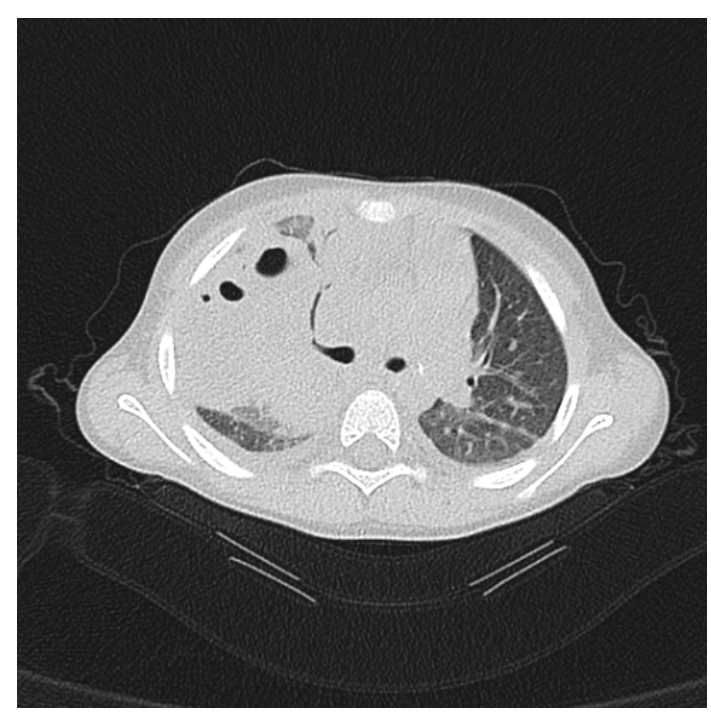

Figure 4. Multiple abscesses in the right upper lobe. Diffuse alveolar consolidations with thickening of intraalveolar spaces in the middle and lower right lobes. Fluid in the right pleural space. Staphylococcus aureus pneumonia with lung abscesses and pleural effusion.

Pleural fluid, if obtained during thoracocentesis or video-assisted thoracoscopic surgery (VATS), should be sent for culture, Gram stain, cytology and molecular techniques if available. Bacteriological investigations should always be undertaken even though they are positive in $1 / 4$ of cases since they may provide useful information guiding antibiotic therapy. Stain for acid-fast bacilli, culture and PCR should also be performed [46]. In most cases of bacterial empyema polymorphonuclear leukocytes are the predominant cells. In case of malignancy the fluid may be blood stained with lymphocytic predominance, although malignant cells may not be present. In tuberculosis there is also predominance of lymphocytes in pleural fluid although in $10 \%$ of cases effusion might be neutrophilic [46]. Light criteria, useful for treatment guidance in adult patients, have not been properly validated in children and their routine use is not recommended $[46,53]$.

All children with empyema or pleural effusion should be treated as inpatients [46]. There is no consensus however as to what is optimal treatment of empyema: antibiotics alone for small to moderate effusions, chest tube insertion with or without fibrinolytics or VATS for moderate to severe cases. Differences in management result to some extent from personal experience and availability of different treatment modalities, including experienced interventional radiologists and pediatric thoracic surgeons. Generally, two most important factors determining the need for chest tube insertion are the size of effusion and the child's degree of respiratory compromise [19]. There is agreement that due to an invasive nature of the procedure and the need for general anesthesia in younger children, a drain should be inserted instead of repeated needle thoracocenteses [46]. According to PIDS, pleural effusions can be divided depending on their size into: 
- Small: $<10 \mathrm{~mm}$ on lateral decubitus radiograph or opacifies $<1 / 4$ hemithorax

- Moderate: $>10 \mathrm{~mm}$ rim of fluid and opacifies $<1 / 2$ hemithorax

- Large: opacifies $>1 / 2$ hemithorax

Conservative treatment with antibiotics is recommended for small effusions. Antibiotic selection is based on blood or pleural fluid culture results, and if these are not available, on treatment guidelines. Many patients improve with conservative treatment alone. In an American study over $50 \%$ of all patients with moderate to severe effusions recovered with antibiotic treatment alone [54]. Management of moderate effusions depends on child's degree of respiratory compromise: if clinical condition is good, treatment with antibiotics is appropriate and if the child presents signs of respiratory distress, treatment is the same as for large effusions: fluid should be removed either by tube thoracocentesis (for not loculated fluid) or chest tube with fibrinolytics or VATS (both for loculated fluid) [19]. Once the chest tube is inserted, no more than $10 \mathrm{ml} / \mathrm{kg}$ of fluid in little children and 1.5 liters of fluid in older children and adolescents should be removed in order to avoid re-expansion pulmonary edema. When this volume is reached, the drain should be clamped for an hour [46]. There is no clear evidence on advantage in clinical outcome of children treated with fibrinolytic agents versus VATS [55,56]. The recommended doses for fibrinolytic agents are $[19,57,58]$ :

- Urokinase (not available in USA) 10,000 U every 12 hours for 3 days in children < 1 year and 40,000 U every 12 hours for 3 days in children $>1$ year

- Streptokinase 12,000 - 25,000 IU/kg/dose daily for 3-5 days

- Tissue plasminogen activator $0.1 \mathrm{mg} / \mathrm{kg}$; maximum of $3 \mathrm{mg}$ three times a day for 3 to 4 days or 4 mg every 24 hours

With streptokinase and urokinase there is risk of hypersensitivity reactions.

Children who fail to improve despite antibiotics, drainage and fibrinolytics, should undergo VATS in order to debride fibrinous adhesions and remove dense loculated fluid. It seems prudent to ask for surgical opinion if the patient is not improving after 7 days of treatment. Another indication for surgery is bronchopleural fistula with pyopneumothorax [46]. As an alternative to VATS, especially in organized empyema in a child with non-resolving signs of systemic infection with fever, formal thoracotomy with decortications should be considered [19]. According to BTS guidelines indications for surgery referral are clinical signs and symptoms and not aberrant radiologic picture in an asymptomatic child [46]. Risk factors for the failure of tube thoracostomy include duration of symptoms $>7$ days before the procedure, complex multiloculated empyema, pneumatocele, pulmonary necrosis and an underlying medical condition [59,60]. A chest tube can be removed if fluid output is $<1 \mathrm{ml} / \mathrm{kg} /$ day calculated over the last 12 hours or 50-60 ml/day and there is no air leak [19].

A more aggressive approach is to perform VATS in the first 48 hours of treatment. That gives a chance for bacteriological diagnosis and shorter hospital stay, though not all studies confirm the latter observation [54]. 
The optimal duration of antibiotic treatment for parapneumonic effusion and empyema depends on clinical response. Recommended route of administration is intravenous until the chest tube is removed, and then can be switched to oral route for 1 to 4 weeks or longer if the child has not fully recovered. However, there are no randomized clinical trials to support this approach $[19,46]$. Long-term outcome in children is favorable. Radiological evidence of pleural disease completely resolves within 3 months in up to $80 \%$ of children and by 18 months in all children. Lung function tests results as well as exercise tolerance in most patients are normal 12 months after discharge [46,52,53]. Conditions predisposing to severe pneumonia with pleural effusion and empyema include immunodeficiencies and cystic fibrosis and they should be excluded during follow-up period [46].

\subsection{Lung abscess}

Lung abscess is a thick-walled cavity containing necrotic tissue $2 \mathrm{~cm}$ or greater in diameter caused by an infection [28]. It may be either primary - occurring in healthy children without lung abnormalities or secondary - occurring in children with underlying condition predisposing to lung disease. The most important mechanism of lung abscess formation is aspiration, especially in children with neuromuscular disorders. Other risk factors include immunodeficiencies, underlying lung disease like congenital malformations, cystic fibrosis, swallowing problems, eg. achalasia, poor dental hygiene. Abscesses may also ensue by hematogenous spread from septicemia or right-sided bacterial endocarditis, extension from foci in abdominal cavity or retropharyngeal space or from airway obstruction by foreign body [61,62].

The main causative organisms are usually streptococci, anaerobic bacteria, S. aureus and Klebsiella pneumonia, however there are rare reports of other causative organisms including Mycoplasma pneumoniae [63]. Mixed infections are common. The most frequent sites for lung abscess formation in recumbent position are: the right upper lobe, the left lower lobe and the apical segments of both lower lobes. When the patient aspirates in supine position the posterior segments of the upper lobes are usually involved.

Clinical symptoms include cough, purulent sputum production, fever, dyspnea, chest pain, tachypnoe, weight loss, hemoptysis, malaise/lethargy. Physical signs do not differ from uncomplicated pneumonia, decreased breath sounds and dull note on percussion may be appreciated. Symptoms may persist for several weeks [61].

Diagnosis is usually made by chest radiograph showing an inflammatory infiltrate of the pulmonary parenchyma with a cavity containing an air-fluid level. Initially it may appear as a solid lesion surrounded by an alveolar infiltrate. Bulging fissure representing increased volume of the affected lobe may be present. CT is usually performed to exclude other complications like empyema, pneumatocoele, underlying congenital abnormality like sequestration, bronchogenic cyst or adenomatoid malformation. Features distinguishing abscess from other entities include well-marginated walls, density greater than water, contrast enhancement in adjacent tissues (Figure 4, Figure 5) [61]. 


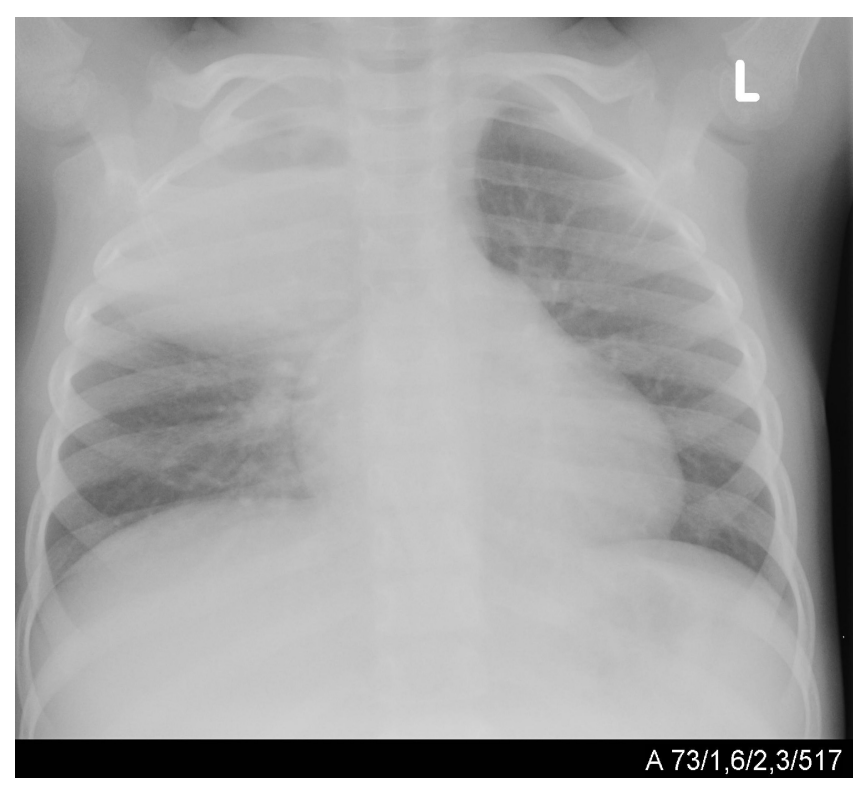

Figure 5. Infiltrate with air-fluid level in the upper field of the right lobe. Lung abscess.

The mainstay of treatment is conservative antibiotic therapy with spectrum covering $S$. pneumoniae, S. aureus and Gram-negative bacilli and anaerobes in case of secondary abscess. For immunocompromised patients antibiotics should cover fungal pathogens. Antibiotic of choice is penicillin with clindamycin or metronidazole. Other experts recommend third-generation cephalosporin and flucloxacillin, ticarcillin, ampicillin/clavulanic acid and piperacillin/tazobactam. One should consider the possibility of MRSA infection, especially if the abscess complicates pneumonia or results from hematogenous spread from other organs [61,62]. A 2-3 week course of intravenous therapy followed by oral treatment for 4 to 8 weeks is usually recommended [28]. In experienced interventional radiology centers CTguided aspiration of the lung abscess and placement of pigtail catheter is performed for diagnostic and therapeutic reasons. Surgical intervention is indicated for abscesses failing to improve despite medical treatment.

The overall outcome is favorable, mortality being much lower than in adults: $<5 \%$ and mostly occurring in children with secondary lung abscesses or underlying medical problems. The complications include empyema or pyopneumothorax if abscess ruptures into pleural cavity, bronchopleural fistula if connection between the abscess cavity and pleural space persists and localized bronchiectasis.

\subsection{Necrotising pneumonia}

Necrotizing pneumonia (NP), defined as multiple cavitary lesions in consolidated areas, is a rare, though increasingly detected complication in children. It is characterized by liquefac- 
tion and cavitation of pulmonary tissue [63]. The most frequently associated pathogen is Streptococcus pneumoniae, especially serotypes 3 and 14. Other pathogens involved include group A Streptococci, Staphylococcus aureus and Mycoplasma pneumoniae [64-68]. The majority of patients have no prior medical history. Necrotizing pneumonia should be suspected in patients with complicated pneumonia who do not improve despite optimal medical treatment. Diagnosis can be established by computed tomography. Radiographic criteria for necrotizing pneumonia include the loss of normal pulmonary parenchymal architecture and the presence of areas of liquefaction replaced within 1-2 days by multiple small cavities [64]. Necrotizing pneumonia often coexists with pleural effusion.

Treatment consists in prolonged course of intravenous antibiotics active against CAP pathogens including resistant strains of $S$. pneumoniae. Interventional procedures are contraindicated in children with NP, as they may increase the risk of complications such as bronchopleural fistula formation [35]. Generally, despite prolonged hospital course and associated morbidity, the long term outcome in most children is favorable. Mortality rates are $5.5-7 \%[28,65]$.

\section{Prevention}

In order to prevent pneumonia several measures can be taken, starting with general recommendations like improving nourishment, housing conditions, heating systems, reducing tobacco smoke exposure, promoting breast-feeding for the first 6 months of age, to more specific infection control measures like hand-washing, avoiding individuals with signs of respiratory tract infections, and vaccinations. For prevention of pneumonia immunization against the following microorganisms is recommended:

- influenza virus

- Streptococcus pneumoniae (conjugate and non-conjugate vaccine)

- Haemophilus influenzae (conjugate vaccine)

- measles virus

- varicella virus

- Bordatella pertussiss

- Mycobacterium tuberculosis

High risk infants: prematurely born $(<35$ week of GA), with hemodynamically significant congenital heart disease, bronchopulmonary dysplasia, congenital abnormalities of the airways and neuromuscular diseases should receive immune prophylaxis with RSV specific monoclonal antibody (palivizumab) in RSV season [68].

AAP recommends the routine use of 13-valent pneumococcal conjugate vaccine (PCV13) for healthy children 2 through 59 months of age and for children 60 through 71 months of age 
with an underlying medical condition that increases the risk of invasive pneumococcal disease (IPD) [69]. Underlying medical conditions that indicate the need for pneumococcal immunization comprise:

- chronic heart disease, in particular cyanotic congenital heart disease and cardiac failure

- chronic lung disease including asthma if treated with prolonged high-dose oral corticosteroids

- diabetes mellitus

- cerebrospinal fluid leaks

- cochlear implant

- functional or anatomical asplenia including children with sickle cell disease and other hemoglobinopathies

- immunocompromising conditions: HIV infection, chronic renal failure and nephrotic syndrome, diseases associated with treatment with immunosuppressive drugs or radiation therapy (including malignant neoplasms, leukemias, lymphomas, Hodgkin disease, solid organ transplantation) and congenital immunodeficiency (including B- (humoral) or Tlymphocyte deficiency; complement deficiencies, particularly C1, C2, C3 and C4 and phagocytic disorders excluding chronic granulomatous disease).

Healthy children $<5$ and children with underlying medical conditions $<6$, who are fully immunized with PCV7 should receive a single supplemental dose of PCV13. Children between 6 and 18 with medical conditions favoring IPD (listed above) should receive a single dose of PCV13 regardless of whether they have previously received PCV7 or PPSV23 (2 doses of PPSV23 recommended). PCV13 which in addition to the 7 serotypes included in PCV7 $(4,6 \mathrm{~B}, 9 \mathrm{~V}, 14,18 \mathrm{C}, 19 \mathrm{~F}, 23 \mathrm{~F})$ contains the 6 pneumococcal serotypes $(1,3,5,6 \mathrm{~A}, 7 \mathrm{~F}, 19 \mathrm{~A})$ responsible for $63 \%$ of cases of invasive pneumococcal disease occurring in children $<5$ in the USA has been licensed by the US Food and Drug Administration in 2010 for use in children between 2 and 71 months of age. Because of the expended coverage provided it is meant to replace PCV7 [69].

\section{Specific bacterial causes of pneumonia}

\subsection{Streptococcus pneumoniae}

Streptococcus pneumoniae is the most common pathogen in CAP in children and the most common cause of pneumonia mortality in children worldwide. It is responsible for at least 1.2 million deaths in infants annually, mostly in sub-Saharan Africa and Asia [45]. There are 92 known pneumococcal serotypes that differ by polysaccharide capsule. It was found that serotypes are correlated with different pneumonia outcomes, study results are not however equivocal. In pediatric patients serotypes 7F, $23 \mathrm{~F}$ and 3 were correlated with the highest risk of death in the course of invasive pneumococcal disease [70]. In another study serotypes 
$1,6,14,19$ were the most prevalent among children with complicated pneumonia, with serotype 1 causing $24.4 \%$ of the complicated cases versus $3.6 \%$ of the uncomplicated cases [71].

S. pneumoniae commonly colonizes epithelium of nasopharynx in $20-40 \%$ of healthy children and $>60 \%$ of infants and children in day-care settings. After colonization a new strain eliminates other competing pneumococcal serotypes and persists for months in a carrier state. Bacteria with so called "persistent colonization phenotype", with low risk of tissue invasion are responsible for perpetual transmission within human populations and induce acquired B-cell mediated immunity to reinfection. To facilitate their stay within nasopharynx and evade host defenses they use different mechanisms like surface adhesions, IgA1 protease and inhibitors of antibacterial peptides. Defects in host defense mechanisms can destroy the balance and lead to infection in immunocompromised host. Another phenotype so called "invasive pneumococcal disease phenotype" is able to spread efficiently from person to person by coughing and rapidly induce the disease. Its main virulence factor is polysaccharide capsule that prevents mechanical clearance by mucous secretions, restricts autolysis, reduces exposure to antibiotics and facilitates invasion and dissemination. Other virulence factors include: pore-forming cytotoxin - pneumolysin that among other pathological effects is able to inhibit cilliary movement of epithelial cells and impairs respiratory burst of phagocytic cells. Recent acquisition of an invasive serotype is more important in terms of further infection than long-term colonization and is in fact recognized as one of definite risk factors for pneumococcal pneumonia [45].

Some of the host immune mechanisms essential for defense against pneumococcal pneumonia are toll-like receptors (TLRs). Children with genetic deficiency of the common TLRadaptor protein - myeloid differentiation primary-response protein 88 (MyD88) or interleukin-1 receptor - associated kinase 4 (IRAK4), a kinase acting directly downstream from MyD88, are especially susceptible to invasive pneumococcal disease. Another genetic factor predisposing to invasive pneumococcal disease is polymorphism of genes coding inhibitors of nuclear factor $\mathrm{\kappa B}$ and defects in the complement $\mathrm{C} 3$ pathway crucial for opsonization and consequently clearance of pneumococci [45].

Pneumonia usually begins with viral upper respiratory tract infection. The pathogen most commonly associated with dual infections with Streptococcus pneumonia is influenza virus. Co-infection with influenza virus attenuates host immune response diminishing its ability to clear pneumococcus. Influenza virus possesses neuraminidase that by exposing certain receptors facilitates pneumococcus' adherence to respiratory epithelium [72]. Local innate immune defense systems like mucociliary clearance, cough reflex, antimicrobial peptides usually succeed in eliminating the pathogen. Should they fail, pneumonia ensues. Clinical symptoms are characteristic for bacterial pneumonia with high fever, chills, malaise, cough and dyspnoea. Cough becomes productive in older children, with purulent, blood tinged sputum. Pleural involvement is quite common. Untreated pneumococcal pneumonia may progress to respiratory failure, septic shock and consequently death.

The usual radiological presentation of pneumococcal pneumonia is lobar pneumonia, frequently accompanied by small pleural effusion. Changes may be confined to a single segment or involve several segments or lobes or present as bronchopneumonia [41]. 
Since universal introduction of pneumococcal conjugated 7-valent vaccine in 2000, there has been a decrease in incidence of pneumococcal pneumonia in children $<5$ [7]. There is, however, concern that the serotypes included in the vaccine can be replaced with previously rare, potentially more virulent serotypes like serotype 1 or 19A [73,74]. Fortunately, these serotypes have been included in the newer conjugated 13-valent vaccine.

There is a problem of increasing antibacterial resistance - up to $10 \%$ of cultured pneumococcal isolates in 2008 in Europe are not susceptible to penicillin, though the impact of in vitro resistance on clinical outcome of patients is not that clear. Fortunately, there was no increase in mortality or complication rate reported in children infected with resistant strains $[71,73,74]$.

\subsection{Staphylococcus aureus}

The incidence of Staphylococcus aureus pneumonia has increased significantly during the past 20 years. An increasing number (up to $76 \%$ in Texas) of community-associated $S$. aureus is methicillin resistant (CA-MRSA) and in some regions it has become the main cause of complicated CAP in children [75-77]. CA-MRSA were described for the first time in the 1990s as a cause of infection in previously healthy young children and adolescents with no prior hospitalization or record with chronic healthcare facilities [77]. There is also significant increase in nasal colonization of healthy children with MRSA in another study from the USA $36.4 \%$ of healthy children were colonized with S. aureus and $9.2 \%$ with MRSA. CA-MRSA has its own genotype different from hospital acquired strains [77]. It is worth noticing that $22 \%$ of MRSA strains had gene locus for PVL, and in a British study $11 \%$ of all S. aureus isolates from pneumonia patients carried the gene $[78,79]$. Even if the impact of nasal colonization on the risk of pneumonia is not clear, since $1 / 3$ of patients with staphylococcal infection had no prior colonization documented [80], these data show a wide distribution of MRSA in the community.

Primary S. aureus pneumonia results from direct invasion of the lungs through the tracheobronchial tree, and secondary pneumonia results from hematogenous spread. S. aureus CAP typically occurs in very young infants: $30 \%$ of cases occur in children younger than 3 months of age and $70 \%$ in those $<1$ year of age, more often in boys [60].CA-MRSA CAP frequently occurs in previously healthy children and adolescents and in many cases is preceded by influenza or flu-like illness or skin and soft tissue infection. Severe respiratory symptoms and hypotension develop rapidly. The USA300 clone is associated with venous thrombosis and subsequent septic pulmonary emboli [77].

S. aureus possesses a variety of virulence factors including surface proteins (eg. protein A) that promote adherence and hence colonization of host tissues, invasions (leukocidin, kinases and hyaluronidase) that promote bacterial spread in tissues and membrane damaging toxins (eg. mentioned above leukocidin). There have been several reports in previously healthy children and adolescents of pneumonia caused by Panton - Valentine leukocidin producing Staphylococcus aureus. The pore-forming toxin encoded by $l u k-S-P V$ and $l u k-F-P V$ genes lyses neutrophils causing exaggerated though ineffective inflammatory response. Patients present with rapidly progressing necrotizing pneumonia manifested by fever, leuco- 
penia and hemoptysis preceded by viral infection, most common influenza [75]. Leucopenia is characteristic for PVL and is thought to be secondary to leukocidin destroying white blood cells [77]. Radiographic appearance is multiple nodular infiltrates, usually unilateral that may transform into cavitary lesions and pneumatocele. Radiographic progression of infiltrates may be very rapid and should raise possibility of $S$. aureus pneumonia. Another characteristic radiographic sign - pneumatoceles - occurs in over half of cases and both its size and number may change hourly [61]. Staphylococcal pneumonia is often complicated with empyema, formation of lung abscesses, pneumothorax and acute respiratory distress syndrome (ARDS).

Given the severe and potentially fatal nature of the infection, prompt initiation of appropriate antibiotic therapy is crucial. For hospitalized patients with pneumonia caused by methicillin susceptible $S$. aureus PIDS recommends intravenous therapy with $\beta$-lactamase stable penicillin (oxacillin, cloxacillin, flucloxacillin or nafcillin) or the first generation cephalosporin (cefazolin). For more severe infections some experts recommend combination therapy with an aminoglycoside or rifampin although data from controlled clinical studies supporting these recommendations are lacking [19]. The first line treatment for hospitalized children suspected of CA-MRSA is vancomycin. There is a concern, however, of adequate concentration of the drug in lung epithelial lining fluid - in adults it has been shown to achieve $18 \%$ of serum levels [77]. Alternative choices are linezolid and clindamycin that have an additional advantage of blocking the production of PVL toxin and staphylococcal exotoxins so they are the drugs of choice in treatment of PVL-CA infections. Clindamycin should be used with care considering local susceptibility data and it should not be used in high inoculum infections such as empyema since in that case there is high risk that the bacteria will constitutively produce methylase [19]. Linezolid achieves higher concentrations in epithelial lining of the lung [80].

\subsection{Mycoplasma pneumoniae}

Mycoplsamas are the smallest self-replicating organisms able to live outside the host cells. They do not have cell wall, but a cell membrane containing sterols and do not stain well with Gram stain and antibiotics disrupting bacterial cell wall like $\beta$-lactams are inactive against these organisms. Mycoplasma pneumoniae pneumonia is usually a mild disease. Transmission occurs via person to person contact and incubation period is usually 1 to 2 weeks. Epidemics occur in approximately 4 - 7 year cycles. Recurrent infections are usual.

Infections with Mycoplasma pneumonia are common. Antibodies are present in $1 / 3$ of all infants between 7 to 12 month of life and over $90 \%$ of adolescents. Very few infections occur in infants in the first 6 months of life probably due to presence of maternal antibodies. Recent studies show that contrary to previous reports M. pneumoniae CAP is also quite common in children $<4$ years. These microorganism are responsible for $1 / 4$ of infections in this age group [81].

Microorganisms are acquired via respiratory route. In the airways they attach to a receptor on respiratory epithelium via adhesions. Lung injury in M. pneumoniae pneumonia is associated with cell-mediated immunity of the host and it is also accompanied by ciliostasis [81]. 
Patients present with symptoms of upper respiratory tract infection, fever, malaise, headache. Symptoms ensue gradually. Cough, which is initially unproductive, appears 3 to 5 days from the onset of disease. Associated symptoms include hoarsness, chills, chest pain, vomiting, nausea, diarrhea and myalgia. Coryza is a rare finding, and pleural effusion occurs in $5-20 \%$ of patients. On auscultation crackles, wheezes and bronchial breathing may be present. Mycoplasma pneumonie may present with extrapulmonary involvement including: nonexudative pharyngitis, cervical lymphadenopathy, otitis media, conjunctivitis, arthritis and rash. Illness usually resolves within 3 - 4 weeks, but it might be more severe in children with sickle cell disease and in Down syndrome. Mycoplasma may cause exacerbations in asthmatic patients [28].

Radiological findings vary from reticular and interstitial pattern to lobar consolidations. Hilar adenopathy is present in $1 / 3$ of patients. Characteristic is poor correlation between clinical symptoms and physical and radiological findings.

Treatment of choice consists in macrolide antibiotics.

In rare cases Mycoplasma pneumoniae pneumonia may be severe with massive lobar consolidation, pleural effusion, lung abscess or pneumatocele formation. Occasionally, fever and radiological changes progress, despite standard macrolide therapy. There is one report of successful treatment of refractory pneumonia with methylprednisolone in children [82]. Rare complications - obliterative bronchiolitis and diffuse interstitial fibrosis - have been described. In 1/3 of children 1 - 2 years after Mycoplasma pneumoniae infection abnormal findings including mosaic perfusion, bronchiectasis, bronchial wall thickening, decreased vascularity and air trapping are observed [81]. Extrapulmonary complications of Mycoplasma pneumonia provoke signs from a variety of organs and systems. These include:

- neural system: meningoencephalitis, transverse myelitis, cranial neuropathy, myeloradiculopathy, a poliomyelitis-like syndrome, psychosis, Guillain-Barré syndrome

- skin: erythematous maculopapular or vesicular exanthems, erythema multiforme, Stevens - Johnson syndrome

- heart: pericarditis, myocarditis, congestive heart failure, heart block

- gastrointestinal tract: nausea, vomiting, diarrhea, hepatic dysfunction, jaundice

- hematologic: hemolytic anemia, thrombocytopenia, disseminated intravascular coagulation

- musculoskeletal: myalgias, arthralgias

- genitourinary: glomerulonephritis, interstitial tubulonephritis

\section{Hospital acquired pneumonia}

Hospital acquired pneumonia (HAP) is defined as pneumonia that occurs 48 hours or more after admission in a patient who had no signs of disease at the time he or she was presenting 
to the hospital [83]. It may be further divided into early onset (48-96 hours after admission) usually caused by pathogens responsible for CAP and late onset ( $>96$ hours after admission) caused by multidrug resistant nosocomial pathogens [84].

Ventilator associated pneumonia (VAP), a type of HAP affecting mechanically ventilated patients is defined as pneumonia that occurs more than 48 hours after intubation [83].

A third type, only recently described, represents health-care associated pneumonia (HCAP) that develops in patients who fulfill one of the following conditions:

- hospitalization for 2 or more days within 90 days of the infection

- residence in a nursing home or long-term care facility

- antibiotic therapy or chemotherapy or wound care within 30 days of the infection

- attending haemodialisis center [83].

Definition of HCAP has not been validated in children, although, due to a growing number of pediatric patients with chronic medical conditions (eg. cerebral palsy, congenital malformation syndromes, chronic pulmonary, heart and renal disease) who frequently have contacts with healthcare personnel, HCAP poses a significant problem in this population.

HAP occurs in $16-29 \%$ of pediatric patients and accounts for $10-15 \%$ of all nosocomial infections in children and up to $67 \%$ of nosocomial infections in children admitted to pediatric intensive care units [85-87]. VAP occurs in about 3 to $32 \%$ of ventilated pediatric ICU patients $[87,88]$. In Europe it is the most common and in the USA second most common nosocomial infection in children treated in intensive care units [88-90]. Mortality in HAP is much higher than in CAP and ranges from 10 to $70 \%$ depending on the etiological factors and comorbidities $[85,86,88]$. HAP and VAP in particular increase length of hospital stay and hospital costs $[86,88,91]$.

The most common etiological factors of pediatric HAP are respiratory viruses including respiratory syncytial virus, adenovirus, influenza and parainfluenza viruses. Bacteria responsible for late onset HAP comprise Gram-negative bacilli: Pseudomonas aeruginosa, Escherichia coli, Klebsiella pneumonia, Acinetobacter spp., Serratia spp.., Gram positive organisms esp. Staphylococcus aureus and coagulase - negative Staphylococci. P. aeruginosa is the most common bacterial pathogen in pediatric intensive care units associated with mortality rates up to $80 \%$ [90]. Most bacteria responsible for nosocomial infections are multidrug resistant, among them methicillin resistant Staphylococci (MRSA) and extended spectrum $\beta$-lactamase (ESBL) producing Gram negative bacilli. Immunocompromised children are at particular risk of infection caused by fungi, esp. Aspergillus, Candida and Pneumocystis jiroveci. In $38 \%$ of cases etiology of VAP in children is polymicrobial [88].

Risk factors for hospital acquired pneumonia comprise intubation and mechanical ventilation (increases the risk 6 to 21-fold increased risk), neuromuscular blockade, length of hospital stay, immunosuppression, recent treatment with antibiotics and H2 blockers as well as overcrowding and understaffing of hospital wards [85,86]. Genetic syndrome, female gender, reintubation, transport out of the intensive care unit, surgery before ICU admission, en- 
teral feeds, use of narcotic medications were found to be independent risk factors of VAP in children [88,91].

Nosocomial pneumonia should be suspected in any child with new respiratory symptoms during hospital stay, hypoxemia, increased oxygen or ventilation requirements, increased amount or altered characteristic of respiratory secretions. Most definitions include clinical and radiological signs, some additional bacteriological and laboratory data [83,92]. According to National Healthcare Safety Network of Centers for Disease Control (CDC), HAP can be diagnosed in patients with new radiological changes (infiltrate, consolidation, cavitation, pneumatocele in infants in the $1^{\text {st }}$ year of life) and at least three clinical criteria (clinically defined pneumonia) or two clinical and one laboratory criteria. For children with underlying pulmonary or heart disease radiologic changes must be confirmed in at least two serial $\mathrm{x}$ rays. Clinical criteria, that must be fulfilled include:

- fever $>38^{\circ} \mathrm{C}$ with no other cause or

- leucopenia $\left(<4,000 / \mathrm{mm}^{3}\right)$ or leucocytosis $\left(\geq 12,000 / \mathrm{mm}^{3}\right)$ and at least one (or two for clinically defined pneumonia) of the following:

- new onset of purulent sputum,

- increase in respiratory secretions,

- change in the character of sputum or respiratory secretions,

- new onset or worsening of respiratory symptoms: cough, tachypnea, dyspnea,

- auscultary findings: rales, bronchial sounds,

- increased oxygen requirements, $\mathrm{PaO}_{2} / \mathrm{FiO}_{2} \leq 240$.

In children up to12 years of age clinical criteria are slightly different and at least three (two in infants $\leq 1$ year of age) must be fulfilled. These include:

- fever $>38^{\circ} \mathrm{C}$ or hypothermia $<36.5^{\circ} \mathrm{C}$ (or temperature instability for infants $\leq 1$ year of age) with no other cause or

- leucopenia $\left(<4,000 / \mathrm{mm}^{3}\right)$ or leukocytosis $\left(\geq 15,000 / \mathrm{mm}^{3}\right)$ and $\geq 10 \%$ immature forms (infants $\leq 1$ year of age)

- new onset of purulent sputum,

- increase in respiratory secretions,

- change in the character of sputum or respiratory secretions,

- new onset or worsening of respiratory symptoms: apnea, cough, tachypnea, dyspnea,

- nasal flaring with chest wall retractions or grunting, wheezing - infants $\leq 1$ year of age

- auscultary findings: rales, bronchial sounds,

- bradycardia ( $<100$ beats/minute) or tachycardia ( $>170$ beats per minute) - infants $\leq 1$ year of age 
- increased ventilation requirements, hypoxemia (Sat $<94 \%$ ) - this condition is obligatory for infants $\leq 1$ year of age.

Laboratory criteria include positive cultures of blood (not related to other infections), pleural fluid or specimens from lower respiratory tract (bronchoalveolar lavage - BAL or protected specimen brushing), intracellular bacteria seen in $\geq 5 \%$ of cells obtained from BAL on direct microscopic exam, histopathologic evidence of abscess formation, focal consolidations, intensive polymorphonuclear cell accumulation in the small airways, lung parenchyma invasion by hyphae or pseudohyphae. Diagnostic value of BAL in children with VAP is found to be $50-72 \%$ and specificity $80-88 \%$, and of quantification of intracellular organisms in BAL samples 30-55\% and 89-95\% respectively [93-96]. Laboratory criteria for HAP caused by atypical bacteria (Mycoplasma spp., Chlamydophila spp., Legionella spp.) or viruses include: positive culture from respiratory secretions, positive detection of antigen or antibody in respiratory secretions, 4-fold IgG rise in paired sera, positive PCR, detection of Legionella pneumophila serogroup 1 antigens in urine [92].

Bacteriological diagnosis is often difficult, since hospitalized patients are commonly colonized with pathogenic flora. Therefore a quantitative criterion of bacterial yield $\left(\geq 10^{4} \mathrm{cfu} / \mathrm{mL}\right.$, or $\geq 10^{4} \mathrm{cfu} / \mathrm{g}$ tissue in case of lung parenchyma specimen) has been established to aid the etiological diagnosis of pneumonia [92]. Applicability of invasive diagnostic techniques (lung biopsy) remains controversial for the fear of complications in unstable or severely sick patients and lack of data confirming their influence on clinical course or mortality rates.

Patients with HAP are most often debilitated individuals with multiple underlying conditions. HAP is a severe disease with high mortality rates. Therefore diagnosis should be established as quickly as possible using a wide array of diagnostic tools and techniques and empiric treatment should be implemented promptly while cultures and other microbiological studies are pending. Antibiotics should have spectrum broad enough to cover gram negative and gram positive bacteria considering previous antibiotic exposure, local flora, antimicrobial susceptibility patterns and guidelines from the infectious diseases specialist. Risk factors for acquisition of antibiotic-resistant gram negative bacteria in pediatric intensive care unit (PICU) patients include younger age, severe general condition (appreciated based on PRISM \{pediatric risk of mortality\} score), intravenous antibiotics administration in the previous 12 months, PICU admission in the past, contacts with chronic care facilities $[87,94]$. Inappropriate antibiotic treatment is associated with increased mortality in patients with HAP [90]. Children with early onset HAP might be treated as those with CAP provided they do not have specific risk factors for HCAP, VAP or colonization with multi-drug resistant bacteria. PICU patients should receive coverage against Pseudomonas aeruginosa (aminoglycoside with an appropriate $\beta$-lactam: piperacillin, ceftazidime or cefepime) and in hospital wards where incidence of methicillin resistant staphylococci or ESBL producing gram negative bacilli exceeds $5 \%$ vancomycin and carbapenems or ureidopenicillin derivative plus $\beta$-lactamase inhibitor respectively should be included in empiric treatment regimes [92]. In children with immunodeficiencies antifungals should be administered. As soon as the causative organism and its sensitivity is known, therapy should be tailored using the 
agent of the narrowest spectrum available. Antibiotics should be administered intravenously and switched to oral route if possible once the patient improves.

Infection control measures that should be meticulously implemented in order to decrease the number of HAP include:

- appropriate hand hygiene, use of gloves

- personal protective equipment - face masks, especially in the periods of increased incidence of respiratory viruses

- cohorting patients infected or colonized with resistant microorganisms

- nursing practices: semirecumbent position for ventilated patients, mouth care

- use of non-invasive ventilation instead of mechanical ventilation in appropriate patients

- care of medical equipment: ventilator circuits, suction devices, pulmonary function testing equipment

- avoiding overcrowding and understaffing

- avoiding $\mathrm{H}_{2}$ antagonists

- judicious use of antibiotics

- immunization practices (as described above for CAP).

\section{Acknowledgements}

The authors wish to thank Katarzyna Jończyk-Potoczna MD, PHD for her excellent assistance with radiological examinations.

\section{Author details}

Irena Wojsyk-Banaszak and Anna Bręborowicz

*Address all correspondence to: iwojsyk@ump.edu.pl

Department of Pulmonology, Pediatric Allergy and Clinical Immunology, Karol Marcinkowski University of Medical Sciences, Szpitalna, Poznań, Poland

\section{References}

[1] World Health Organization. Pneumonia. Fact sheet No. 331.2011. Available at www.who.int/mediacentre/factsheets/fs331/en. Accessed 03.08.2012 
[2] Singh V, Aneja S. Pneumonia - management in the developing World. Pediatr Respir Rev 2011;12:52-59

[3] Senstad AC, Suren P, Brauteset L, Eriksson JR, Hoiby EA, Wathne KO. Community acquired pneumonia (CAP) in children in Oslo. Norway. Acta Paediatr 2009;98:332-336

[4] Clark JE, Hammal D, Hampton F, Spencer D, Parker L. Epidemiology of community acquired pneumonia in children seen in hospital. Epidemiol Infect 2007;135:262-9

[5] Myles PR, MC Keever TM, Pogson Z, Smith CJ, Hubbard RB. The incidence of pneumonia using data from a computerized general practice database. Epidemiol Infect 2009; 137:709-716

[6] Weigl JA, Puppe W, Belke O, Neususs J, Bagci F, Schmitt HJ. Population-based incidence of severe pneumonia in children in Kiel, Germany. Klin Pediatr 2005;217:211-9

[7] Harris M, Clark J, Coote N, Fletcher P, Harnden A, McKean M, Thomson A. on behalf of the British Thoracic Society Standards of Care Committee. British Thoracic Society guidelines for the management of community acquired pneumonia in children: update 2011. Thorax 2011; 66:ii1-ii23

[8] Grijalva CG. Recognising pneumonia burden through prevention. Vaccine 2009;27S:C6-C8

[9] Lee GE, Lorch SA, Sheffler-Collins S, Kronman MP, Shah SS. National hospitalization trends for pediatric pneumonia and associated complications. Pediatrics 2010;126:204-213

[10] Roxburgh CS, Youngson GG, Townend JA, Turner SW. Trends in pneumonia and empyema in Scottish children in the past 25 years. Arch Dis Child 2008;93:316-318

[11] Michelow IC, Olsen K, Lozano J, Rollins NK, Duffy LB, Ziegler T, Kauppila J, Leinonen M, McCracken GH Jr.. Epidemiology and clinical characteristic of community acquired pneumonia in hospitalized children. Pediatrics 2004;113:701-7

[12] Virkki R, Juven T, Rikalainen H, Svedestrom E, Mertsola J, Ruuskanen O. Differentiation of bacterial and viral pneumonia in children. Thorax 2002;57:438-41

[13] Don M, Canciani M, Korppi M. Community - acquired pneumonia in children: what's old? What's new? Acta paediatrica 2010;99:1602-1608

[14] Principi N, Esposito S, Blasi F, Allegra L; Mowgli study group. Role of Mycoplasma pneumoniae and Chlamydia pneumoniae in children with community - acquired lower respiratory tract infections. Clin Infect Dis 2001;32:1281-9

[15] Baer G, Engelcke G, Able-Horn M, Schaad UB, Heininger U. Role of Chlamydia pneumoniae and Mycoplasma pneumoniae as causative agents of community - acquired pneumonia in hospitalised children and adolescents. Eur J Clin Microbiol Infect Dis 2003;22:742-5 
[16] Tsolia MN, Psarras S, Bossios A, Audi H, Paldanius M, Gourgioyis D, Kallergi K, Kafetzis DA, Constantopoulos A, Papadopoulos NG. Etiology of community acquired pneumonia in hospitalized school-age children: Evidence for high prevalence of viral infections. Clin Infect Dis 2004;39:681-686

[17] Van der Poll T, Opal SM. Pathogenesis, treatment and prevention of pneumococcal pneumonia. Lancet 2009;274:1543-56

[18] Isaacman DJ, McIntosh ED, Reinert RR. Burden of invasive pneumococcal disease and serotype distribution among Streptococcus pneumoniae isolates in young children in Europe: impact of the 7-valent pneumococcal conjugate vaccine and considerations for future conjugate vaccines. Int J Infect Dis 2010;14:e197-209

[19] Bradley JS, Byington CL, Shah SS, Alverson B, Carter ER, Harrison C, Kaplan SL, Mace SE, McCracken GH Jr, Moore MR, St Peter SD, Stockwell JA, Swanson JT, Pediatric Infectious Diseases Society and the Infectious Diseases Society of America. The management of community - acquired pneumonia in infants and children older than 3 months of age: Clinical Practice Guidelines by the Pediatric Infectious Diseases Society and the Infectious Diseases Society of America. Published by Oxford University Press on behalf of the Infectious Diseases Society of America. DOI: 10.1093/cid/cir531

[20] Graham SM. Child pneumonia: current status, future prospects. Int J Tuberc Lung Dis 2010;14:1357-61

[21] Suzuki M, Thiem VD, Yanai H, Matsubayashi T, Yoshida L-M, Tho LH, Minh TT, Anh DD, Kilgore PE, Ariyoshi K. Association of environment tobacco smoking exposure with an increased risk of hospital admissions for pneumonia in children under 5 years of age in Vietnam. Thorax 2009; 64:484-489

[22] Talbot TR, Hartet TV, Mitchel E, Halasa N, Arbogast PG, Poehling KA, Schaffner W, Craig AS, Griffin MR. Asthma as a risk factor for invasive pneumococcal disease. N Engl J Med. 2005;352:2082-2090

[23] Coote N, McKenzie S. Diagnosis and investigation of bacterial pneumonia. Pediatric Respir Rev. 2000;1:8-13

[24] Mathews B, Shah S, Cleveland RH, Lee EY, Bachur RG, Neuman MI. Clinical predictors of pneumonia among children with wheezing. Pediatrics 2009;124:e29-36

[25] Cardoso MRA, Nascimento - Carvalho CM, Ferrero F, Alves F, Cousens SN. Adding fever to WHO criteria for diagnosing pneumonia enhances the ability to identify pneumonia cases among wheezing children. Arch Dis Child doi:10.1136/adc. 2010.189894

[26] Craig JC, Williams GJ, Jones M, Codarini M, Macaskill P, Hayen A, Irwig L, Fitzgerald DA, Isaacs D, McCaskill M. The accuracy of clinical symptoms and signs for the diagnosis of serious bacterial infection in young febrile children: prospective cohort study of 15781 febrile illnesses. BMJ 2010;340:c1594 
[27] Thomson AH. Treatment of community-acquired pneumonia in children. Clin Pulm Med 2008;15:283-292

[28] Light M.J. Pneumonia. In: Light M.J. (ed.) Pediatric Pulmonology. Policy of the American Academy of Pediatrics. American Academy of Pediatrics; 2011. p 392-421

[29] Don M, Valent F, Korppi M, Canciani M. Differentiation of bacterial and viral community - acquired pneumonia in children. Pediatr Int 2009;51:91-96

[30] Korppi M, Remes S, Heiskanen - Kosma T. Serum procalcitonin concentrations in bacterial pneumonia in children: a negative result in primary healthcare settings. Pediatr Pulm 2003;35:56-61

[31] Khan DA, Rahman A, Khan FA. Is procalcitonin better than C-reactive protein for early diagnosis of bacterial pneumonia in children? J Clin Lab Anal 2010;24 (1):1-5

[32] Flood RG, Badik J, Aronoff SC. The utility of serum C- reactive protein in differentiating bacterial from non-bacterial pneumonia in children: a meta-analysis of 1230 children. Pediatr Infect Dis J 2008;27:95-9

[33] Schuetz P, Christ-Crain M, Thomann R, Falconnier C, Wolbers M, Widmer I, Neidert S, Fricker T, Blum C, Schild U, Regez K, Schenenberger R, Henzez C, Bregenzer T, Hoess C, Krause M, Bucher HC, Zimmerli W, Mueller B. for the proHOSP Study Group. Effect of procalcitonin-based guidelines vs standard guidelines on antibiotic use in lower respiratory tract infections. The ProHOSP randomized controlled trial. JAMA 2009;302:1059-1066

[34] Muller F, Christ-Crain M, Bregenzer T, Krause M, Zimmerli W, Mueller B, Schuetz P, for the proHOSP Study Group. Procalcitonin levels predict bacteremia in patients with community - acquired pneumonia. CHEST 2010;138:121-129

[35] Sandora TJ, Harper MB. Pneumonia in hospitalized children. Pediatr Clin N Am 2005;52:1059-81

[36] Lahti E, Peltola V, Waris M, Virkki R, Rantakokko - Jalava K, Jalava J, Eerola E, Ruuskanen O. Induced sputum in the diagnosis of childhood community - acquired pneumonia. Thorax 2009;64:252-257

[37] Requejo HI, Guerra ML, Dos Santos M, Cocozza AM. Immunodiagnoses of community - acquired pneumonia in childhood. J Trop Pediatr 1997;43:208-12

[38] Le Monnier A, Carbonnelle E, Zahar JR, Le Bourgeois M, Abachin E, Quesne G, Varon E, Descamps P, De Blic J, Scheinmann P, Berche P, Ferroni A. Microbiological diagnosis of empyema in children: comparative evaluations by culture, polymerase chain reaction and pneumococcal antigen detection in pleural fluids. Clin Infect Dis 2006;42:1135-40

[39] Rello J, Lisboa T, Lujan M, Gallego M, Kee C, Kay I, Lopez D, Waterer GW; DNANeumococo Study Group. Severity of pneumococcal pneumonia associated with genomic bacterial load. Chest 2009;136:832-40 
[40] Ferrero F, Nascimento - Carvalho CM, Cardoso MR, Camargos P, March M-Fp, Berezin E, Ruvinsky R, Sant'Anna C, Feris-Iglesias J, Maggi R, Benguigui Y, CARIBE group. Radiographic findings among children hospitalized with severe community acquired pneumonia. Pediatr Pulm 2010;45:1009-13

[41] Vilar J, Domingo ML, Doto C, Cogollos J. Radiology of bacterial pneumonia. Eur J Radiol 2004;51:102-13

[42] Gibson NA, Hollman AS, Payton JY. Value of radiological follow up of childhood pneumonia. BMJ 1993;307:1117

[43] Argawal D, Awasthi S, Kabra SK, Kaul A, Singhi S, Walter SD; ISCAP Study Group. Three day versus five day treatment with amoxicillin for non-severe pneumonia in young children: a multicentre randomized controlled trial BMJ 2004;328:791 (erratum BMJ 2004;328:1066)

[44] Quazi S. Clinical efficacy of 3 days versus 5 days of oral amoxicillin for treatment of childhood pneumonia: a multicentre double-blind trial. Lancet 2002;360:835-41

[45] Atkinson M, Lakhanpaul M, Smyth A. Comparison of oral amoxicillin and intravenous benzyl penicillin for community acquired pneumonia in children (PIVOT trial): a multicentre pragmatic randomized controlled equivalence trial. Thorax 2007;62:1102-6

[46] Balfour -Lynn IM, Abrahamson E, Cohen G, Hartley J, King S, Parikh D, Spencer D, Thomson AH, Urquhart D, on behalf of the Pediatric Pleural Diseases Subcommittee of the BTS Standards of Care Committee. BTS guidelines for the management of pleural infection in children. Thorax 2005;60(Suppl I):i1-i21

[47] Puligandla PS, Laberge JM. Respiratory infections: Pneumonia, lung abscess and empyema. Sem Pediatr Surg 2008;17:42-52

[48] Li S-TT, Tancredi DJ. Empyema hospitalization increased in US children despite pneumococcal conjugate vaccine. Pediatrics 2010;125:26-33

[49] Byington CL, Spencer LY, Johnson TA, Pavia AT, Allen D, Mason EO, Kaplan S, Carroll KC, Daly JA, Christenson JC, Samore MH. An epidemiological investigation of a sustained high rate of pediatric parapneumonic empyema: risk factors and microbiological associations. Clin Infect Dis 2002;34:434-40

[50] Lahti E, Peltola V, Virkki R, Alanen M, Ruuskanen O. Development of parapneumonic empyema in children. Acta Paediatr 2007:96:1686-92

[51] Buckingham SC, King MD, Miller ML. Incidence and etiologies of complicated parapneumonic effusions in children 1996 to 2001. Pediatr Infect Dis J 2003;22:499-504

[52] Barnes NP, Hull J, Thomson AH. Medical management of parapneumonic pleural disease. Pediatr Pulmon 2005;39:127-134

[53] Jaffe A, Balfour -Lynn IM. Management of empyema in children. Pediatr Pulmon 2005;40:148-156 
[54] Carter E, Waldhausen J, Zhang W, Hoffman L, Redding G. Management of children with empyema: plural drainage is not always necessary. Pediatr Pulmon 2010;45:475-480

[55] Sonnappa S, Cohen G, Owens CM, van Doorn C, Cairns J, Stanojevic S, Elliott MJ, Jaffe A. Comparison of urokinase and video - assisted thoracoscopic surgery for treatment of childhood empyema. Am J Respir Crit Care Med 2006;174:221-227

[56] St Peter SD, Tsao K, Harrison C, Jackson MA, Spilde TL, Keckler SJ, Sharp SW, Andrews WS, Holcomb GW, Ostile DJ. Thoracoscopic decortications vs tube thoracostomy with fibrinolysis for empyema in children: a prospective, randomized trial. J Pediatr Surg 2009;44:106-111

[57] Yao C-T, Wu J-M, liu C-C, Wu M-H, Chuang H-Y, Wang J-N. Treatment of complicated parapneumonic pleural effusion with intrapleural streptokinase in children. Chest 2004;125:566-71

[58] Feola GP, Shaw CA, Coburn L. Management of complicated parapneumonic effusions in children. Techniques Vasc Radiol 2003;6:197-204

[59] Jamal M, Reebye SC, Zamakhshary M, Skarsgard ED, Blair GK. Can we predict the failure of thoracostomy tube drainage in the treatment of pediatric parapneumonic collections? J Ped Surg 2005;40:838-41

[60] Margenthaler JA, Weber TR, Keller TS. Predictors of surgical outcome for complicated pneumonia in children: impact of bacterial virulence. World J Surg 2004;28:87-91

[61] Crawford SE, Daum RS. Bacterial pneumonia, Lung Abscess and Empyema. In: Taussig LM, Landau LI. Pediatric respiratory medicine, Mosby Elsevier. Philadelphia 2008:501-553

[62] Patradoon-Ho P, Fitzgerald DA. Lung abscess in children. Pediatr Resp Rev 2007;8:77-84

[63] Leonardi S, del Giudice MM, Spicuzza L, Saporito M, Nipitella G, La Rossa M. Lung abscess in a child with Mycoplasma pneumoniae infection. Eur J Pediatr 2010;169:1413-1415

[64] Sawicki GS, Lu FL, Valim C, Cleveland RH, Colin AA. Necrotising pneumonia is an increasingly detected complication of pneumonia in children. Eur Respir J 2008;31:1285-1291

[65] Hacimustafaoglu M, Celebi S, Sarimehmet H, Gurpinar A, Ercan I. Necrotizing pneumonia in children. Acta Paediatr 2004;93:1172-1177

[66] Bender JM, Ampofo K, Korgenski K, Daly J, Pavia AT, Mason EO, Byington CL. Pneumococcal necrotizing pneumonia in Utah: Does serotype matter? Clin Infect Dis 2008;46:1346-52 
[67] Hsieh Y-C, Hsiao C-H, Tsao P-N, Wang J-Y, Hsueh P-R, Chiang B-L, Lee W-S, Huang L-M. Necrotizing pneumococcal pneumonia in children: the role of pulmonary gangrene. Pediatr Pulmonol 2006;41:623-629

[68] American Academy of Pediatrics. Policy statement - modified recommendations for use of palivizumab for prevention of respiratory syncytial virus infections

[69] American Academy of Pediatrics. Policy statement - Recommendations for the prevention of Streptococcus pneumoniae Infections in Infants and Children: Use of 13Valent Pneumococcal Conjugate Vaccine (PCV13) and Pneumococcal Polysaccharide Vaccine (PPSV23). Pediatrics DOI: 10.1542/peds.2010-1280

[70] Ruckinger S, von Kries R, Siedler A, van der Linden M. Association of serotype of Streptococcus pneumonia with risk of severe and fatal outcome. Pediatr Infect Dis J 2009;28:118-122

[71] Tan TQ, Mason EO Jr, Wald ER, Barson WJ, Schutze GE, Bradley JS, Givner LB, Yogev R, Kim KS, Kaplan SL. Clinical characteristic of children with complicated pneumonia caused by Streptococcus pneumonia. Pediatrics 2002;110:1-6

[72] McCullers JA. Insights into the interaction between influenza virus and Pneumococcus. Clin Microb Rev 2006;19:571-582

[73] Prayle A, Atkinson M, Smyth A. Pneumonia in the developed world. Pediatr Resp Rev 2011:12;60-69

[74] Wexler ID, Knoll S, Picard E, Villa Y, Shoseyov D, Engelhard D, Kerem E. Clinical characteristics and outcome of complicated pneumococcal pneumonia in pediatric population. Pediatr Pulmon 2006;41:726-734

[75] Gonzalez BE, Hulten KG, Dishop MK, Lamberth LB, Hammerman WA, Mason EO Jr, Kaplan SL. Pulmonary manifestations in children with invasive community acquired Staphylococcus aureus infection. Clin Infect Dis 2005;41:583-90

[76] Defres S, Marwick C, Nathwani D. MRSA as a cause of lung infection including airway infection, community-acquired pneumonia and hospital acquired pneumonia. Eur Resp J 2009;34:1470-1476

[77] Shilo N, Quach C. Pulmonary infections and community associated methicillin resistant Staphylococcus aureus: A dangerous mix? Pediatr Respir Rev 2011;12:182-189

[78] Creech CB, Kernodle DS, Alsentzer A, Wilson C, Edwards KM. Increasing rates of nasal carriage of methicillin-resistant Staphylococcus aureus in healthy children. Pediatr Infect Dis J 2005;24:617-621

[79] Holmes A, Ganner M, McGuane S, Pitt TL, Cookson BD, Kearns AM. Staphylococcus aureus isolates carrying Panton - Valentine leukocidin genes in England and Wales: frequency, characterization and association with clinical disease. J Clin Microbiol 2005;43:2384-90 
[80] Wallin TR, Hern G, Frazee BW. Community - associated methicillin resistant Staphylococcus aureus. Emerg Med Clin North Am. 2008;26:431-55

[81] Shehab ZM. Mycoplasma Infections. In: Taussig LM, Landau LI. Pediatric respiratory medicine, Mosby Elsevier. Philadelphia 2008:615-620

[82] Tamura A, Matsubara K, Tanaka T, Nigami H, Yura K, Fukuya T. Methylprednisolone pulse therapy for refractory Mycoplasma pneumoniae pneumonia in children. J Infect 2008;57:223-228

[83] American Thoracic Society Documents. An official statement of the American Thoracic Society and the Infectious Diseases Society of America. Guidelines for the management of Adults with hospital - acquired, ventilator associated and healthcare associated pneumonia. Am J Respir Crit Care Med 2005;171:388-416

[84] Rotstein C, Evans G, Born A, Grossman R, Light RB, Magder S, McTaggart B, Weiss $\mathrm{K}$, Zhanel GG. Clinical practice guidelines for hospital - acquired pneumonia and ventilator-associated pneumonia in adults. Can J Infect Dis Med Microbiol 2008;19:19-53

[85] Zar HJ, Cotton MF. Nosocomial pneumonia in pediatric patients. Practical problems and rational solutions. Pediatr Drugs 2002;4:73-83

[86] Bigham MT, Amato R, Bondurrant P, Fridriksson J, Krawczeski CD, Raake J, Ryckman S, Schwartz S, Shaw J, Wells D, Brill RJ. Ventilator - associated pneumonia in the pediatric intensive care unit: characterizing the problem and implementing a sustainable solution. J Pediatr 2009;154:582-7

[87] Foglia E, Meier MD, Elward A. Ventilator - associated pneumonia in neonatal and pediatric intensive care unit patients. Cil Microbiol Rev 2007;20:409-425

[88] Srinivasan R, Asselin J, Gildengorin G, Wiener-Kronish J, Flori HR. A prospective study of ventilator - associated pneumonia. Pediatrics 2009;123:1108-1115

[89] Raymond J, Aujard Y. European Study Group. Nosocomial infections in pediatric patients: a European, multicenter prospective study. Infect Control Hosp Epidemiol $2000 ; 21: 260-263$

[90] Richards MJ, Edwards JR, Culver DH, Gaynes RP. Nosocomial infections in pediatric intensive care units in the United States. National Nosocomial Infections Surveillance System. Pediatrics 1999;103:E39

[91] Elward AM, Warren DK, Fraser VJ. Ventilator-associated pneumonia in pediatric intensive care unit patients: risk factors and outcomes. Pediatrics 2002;109:758-764

[92] Horan TC, Andrus M, Dudeck MA. CDC/NHS surveillance definition of health care -associated infection and criteria for specific types of infections in the acute care setting. Am J Infect Control 2008;36:309-32 
[93] Gauvin F, Dassa C, Chaibou M, Proulx F, Farrel CA, Lacroix J. Ventilator-associated pneumonia in intubated children: comparison of different diagnostic methods. Pediatr Crit Care Med 2003;4:437-443

[94] Toltzis P, Hoyen C, Spinner - Block S, Salvator AE, Rice LB. Factors that predict preexisting colonization with antibiotic - resistant gram - negative bacilli in patients admitted to a pediatric intensive care unit. Pediatrics 1999;103:719-723

[95] Labenne M, Poyart C, Rambaud C, Goldfarb B, Pron B, Jouvet P, Delamare C, Sebag $G$, Hubert P. Blind protected specimen brush and bronchoalveolar lavage in ventilated children. Crit Care Med 1999; 27:2537-2543

[96] Masterton RG, Galloway A, French G, Street M, Armstrong J, Brown E, Cleverley J, Dilworth P, Fry C, Gascoigne AD, Knox A, Nathwanii D, Spencer R, Wilcox M. Guidelines for the management of hospital acquired pneumonia in the UK: report of the working party on hospital - acquired pneumonia of the British Society of Antimicrobial Chemotherapy. J Antimicrob Ther 2008;62:5-34 
